Реферат. В статье анализируется роль Google Book Search, крупнейшего корпоративного хранилища информации с подчиненной функцией платного доступа, в выработке новой институциональной парадигмы электронных библиотек. Отмечается негативная реакция зарубежного библиотечного сообщества на функционирование книжного сервиса IT-гиганта как попытки монополизации доступа к интеллектуальному достоянию. Рассказывается о концепции общественной пользы, инициировавшей образование новых электронных хранилищ.

Рассмотрен альтернативный опыт формирования и функционирования ряда зарубежных электронных библиотек: HathiTrust Digital Library, Europeana, Digital Public Library of America, Internet Archive, выдвигающих как приоритет некоммерческий доступ к базам данных. Описываются история возникновения и основные структурные параметры формирующихся электронных собраний. Проанализирована динамика взаимоотношений новых электронных библиотек с книжным cepвисом Google - oт активного сотрудничества в программах оцифровки фондов к противостоянию монопольной практике информатизации, а затем к спорадическому взаимодействию в рамках специальных проектов, продвигающих новый формат предоставления информационных услуг. Уделяется внимание выработке новых принципов коллективного сотрудничества электронных библиотек за рубежом в процессе формирования инфраструктуры информационного общества.

Ключевые слова: информационное общество, проект Google Book Search, электронная библиотека, проект «Гутенберг», Live Book Search, HathiTrust Digital Library, Europeana, Digital Public Library of America, Internet Archive.

Для цитирования: Савицкая T.E. Проект Google Book Search и альтернативный опыт формирования электронных библиотек // Библиотековедение. 2016. Т. 65, № 5. С. 522-530.

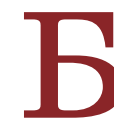
урная интернетизация социума, замещение на волне всеобщей компьютеризации разнообразных форм социально-культурной деятельности их электронными аналогами открывают перед библиотеками новые перспективы. Поистине знаком времени становится опережающее развитие электронных библиотек как базового элемента рождающейся инфраструктуры информационного общества. В то же время впечатляющий опыт стремительного развертывания книжного сервиса IT-гиганта Google, превратившегося в крупнейшее в мире корпоративное хранилище информации с подчиненной функцией платного доступа ${ }^{1}[1]$, продемонстрировал трудности, стоящие перед создателями электронных коллекций (Google столкнулся с невозможностью использовать значительную часть собранного материала по причине вызвавших судебное преследование массовых нарушений авторских прав).

Финансовый размах и технологический успех Google Book Search - крупнейшего брокера на информационном рынке с 2004 г. (времени начала проекта), развертывались в контексте

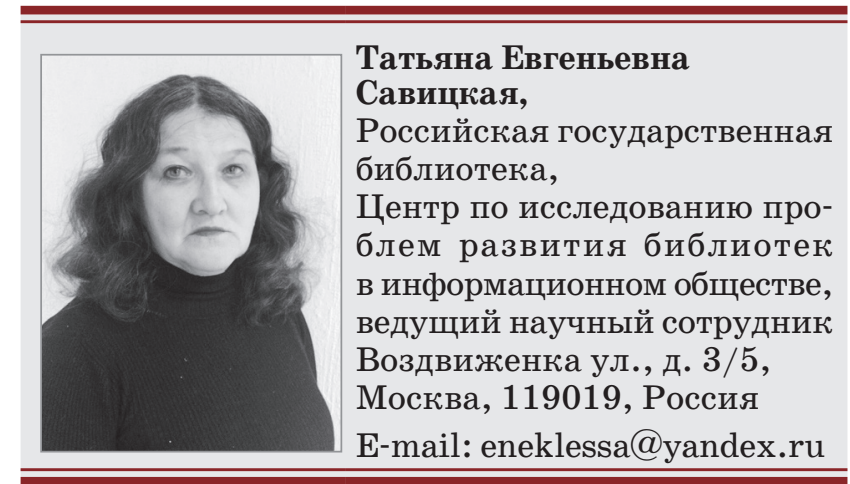

нарастающего сопротивления широких кругов интернет-общественности попытке монополизации частной корпорацией доступа к мировому интеллектуальному наследию. Как отметил основатель Альянса открытого контента (Open Content Alliance, OCA), известный интернет-предприниматель Б. Кейл ${ }^{2}$, Google выстроил скорее частную библиотеку отдельной корпорации, нежели общественный ресурс, приходится сомневаться в пользе сотрудничества с ним для библиотек [2]. 
Безусловно, коммерческие интересы глобального бренда, выработавшего в результате соглашений с книгоиздателями и ограниченным кругом авторов весьма эффективные бизнес-модели распространения оцифрованных изданий, вступили в резкое противоречие с интересами, в первую очередь, научного и библиотечного сообществ, отстаивающих принцип всеобщего доступа к информации как некий цивилизационный стандарт, незыблемое достижение демократии. Однако было бы ошибкой, на наш взгляд, усматривать в неприятии библиотеками коммерческих моделей, превращающих онлайн-трансляцию текстов в средство наживы через размещение на полях таргетированной рекламы, некий узковедомственный подход, маскирующий неумение гуманитарных институций эффективно существовать по правилам глобального рынка. Этот конфликт имеет более глубокие корни. С момента зарождения электронной цивилизации она была (и ныне остается) ареной жесткого противостояния двух непримиримых тенденций: тенденции к расширению общедемократического потенциала информационно-коммуникативных технологий (неуклонное расширение Сети, основанное на принципе всеобщего доступа; бесплатное распространение программного обеспечения на начальном этапе развития до возникновения компаний Microsoft и Apple; создание интернет-ресурсов по модели коллективного участия) и тенденции к прогрессирующей монетизации интернет-практик (приватизация больших массивов персональных данных как ресурс капитализации IT-гигантов, засилье контекстной и таргетированной рекламы, расцвет интернет-маркетологии).

Не желая в процессе формирования электронных коллекций копировать методы действия IT-гиганта, лидеры библиотечного сообщества были вынуждены выработать собственные стратегии информатизации знания, объединяя потенциал новейших информационно-коммуникативных технологий с общепризнанной концепцией общественной пользы. Ознакомимся с главнейшими из этих интересных начинаний.

\section{Взирая на Google: альтернативные стратегии информатизации знания}

История формирования зарубежных электронных библиотек началась задолго до появления компании Google c ее фирменным поисковиком Back Rub, ставшим залогом ее успешности. В 1971 г., еще до изобретения Интернета, М. Харт оцифровал Декларацию независимости США, ставшую первым электронным документом находящегося в свободном доступе собрания, получившего позднее наименование проект «Гутенберг» (к октябрю 2015 г. в нем насчитывалось 50 тыс. ед. хр.) [3]. В 1996 г. в Сан-Франциско под руководством Б. Кейла начал действовать Internet
Archive, некоммерческая электронная библиотека с заявленной миссией универсального доступа ко всему знанию. Крупная организация с 33 центрами оцифровки, расположенными в пяти странах, к середине 2013 г. располагала коллекцией в 4,4 млн книг, ежемесячно распространяя свыше 15 млн электронных копий [4].

На рубеже XX-XXI вв. собственными программами оцифровки обзавелись библиотеки крупнейших американских университетов. Скромные объемы оцифрованного материала, ограниченная мощность сканирующих устройств и недостаточность средств для осуществления собственных эффективных программ оцифровки подтолкнули университетские библиотеки к сотрудничеству c Google. Как отмечали в 2007 г. Дж. Грог и Б. Эшмор ${ }^{3}$, библиотечный проект Google Search Book исключительно привлекателен, поскольку у Google есть знания и ресурсы для того, чтобы довести до должного уровня существующие библиотечные программы оцифровки при весьма доступных бюджетных вливаниях практически бесплатно [2]. Когда же выяснилось, что полученные фактически даром бесценные коллекции научных библиотек были незамедлительно инкорпорированы в «свободную глобальную торгово-рекламную систему» [5] всемирного бренда с целью извлечения выгоды, общественность возмутилась против незаконного приобретения собственности с целью коммерческого использования (из заявления Ассоциации американской университетской прессы (Association of American University Presses, AAUP), кражи интеллектуальной собственности (по выражению П. Шредер, президента Американской ассоциации издателей - организации, вскоре выступившей с масштабным иском к корпорации).

Осознав, что Google внедряет коммерческие модели, которые «взрывают» весь библиотечный usus $^{4}$ [6], научное сообщество вступило на путь поиска таких стратегий информатизации знания, которые не противоречили бы фундаментальной просветительской миссии библиотеки как социально-культурной институции. Оригинальные версии общедоступных цифровых библиотек предложили: консорциум HathiTrust Digital Library (действует с 2008 г.); Europeana, библиотечный проект ЕС (запущен также в 2008 г.); Всемирная цифровая библиотека (World Digital Library), проект Библиотеки Конгресса США при содействии ЮНЕСКО (доступна с 2009 г.); Цифровая публичная библиотека Америки (Digital Public Library of America (DPLA)), открытая в 2013 году).

Руководствуясь концепцией общественной пользы как сверхзадачей, инициировавшей образование новых электронных хранилищ, лидеры библиотечного сообщества прекрасно осознавали отличие собственной институциональной миссии от узко прагматических целей, преследуемых Google. П. Куран, декан библиотечной 
системы Мичиганского университета, заявил, что Google - это корпорация с чувством ответственности по отношению к партнерам, компания может процветать 50 лет, 100 лет, 1000 лет; мы академическая институция с обязательством сохранять и использовать знания гуманитарных наук, равно как их печатные носители, в перспективе безграничного будущего [7].

Некоммерческий доступ к базам данных как приоритет был положен в основу HathiTrust Digital Library ${ }^{5}$, консорциума библиотечных систем американских университетов Среднего Запада (университеты Мичигана, Айовы, Иллинойса) и 11 библиотек университетской системы Калифорнии. Заявляя себя как безопасное распределенное хранилище данных, принадлежащих партнерской группе крупных научных библиотек и управляемой ими [8], библиотека ставит перед собой следующие задачи: формирование авторитетного цифрового архива; создание новой открытой технологической инфраструктуры, облегчающей доступ к собранным материалам; обеспечение безопасности их сохранения; актуальная поддержка сотрудничества между библиотеками - членами консорциума из США, Канады и Европы (к 2013 г. число их доходило до 60).

Сформированная на основе объединения в гигантскую базу данных цифровых копий, оставшихся в распоряжении библиотек в результате сотрудничества с книжным проектом Google (с добавлением копий, полученных из Internet Archive; от Live Book Search, программы оцифровки книг от Microsoft, а также собственноручно отсканированных материалов), HathiTrust Digital Library к началу 2013 г. располагала 10599355 ед. хр. общим объемом в 3709774250 страниц [9]. Демонстрируя динамику активного роста, фонды библиотеки в октябре 2015 г., согласно информации на сайте консорциума, насчитывали уже 13,7 млн книг, из которых 5,3 млн относились к общественно доступным, т. е. текстам, опубликованным в США до 1923 г., а вне страны - до 1873 года. Значительная часть контента HathiTrust Digital Library, в конце 2013 г. определяемая в $68 \%$ всего объема [10], находится в зоне действия авторского права; свыше 12 тыс. томов из состава коллекции лицензированы общественной организацией Creative Commons ${ }^{6}$ как свободно доступные. Тем не менее в ходе двух судебных разбирательств (в сентябре 2011 г. и в июне 2014 г.), инициированных Гильдией американских авторов против библиотечного консорциума, за ним было признано право добросовестного использования.

На волне активного противодействия «гуглизации» всемирного интеллектуального наследия были сформированы две крупнейшие, весьма перспективные электронные библиотеки: паневропейский проект EC Europeana и претендующая на статус национальной библиотеки DPLA. Импульс к запуску Europeana дал жћ.-Н. Ж Жанней, тогдашний директор Национальной библиотеки Франции, занявший бескомпромиссную позицию сопротивления культурной экспансии глобального бренда как новому проявлению американского культурного империализма [11]. Затем проект был поддержан властными структурами ЕС.

Доступная для пользователей с 20 ноября 2008 г. многоязычная мультимедийная Europeana к сентябрю 2012 г. аккумулировала свыше 20 млн ед. хр., включая книги, журналы, изобразительные материалы, музыкальные записи, отражающие культурное наследие народов Европы [12]. Europeana строится по модели децентрализованного хранилища данных, объединяя национальные цифровые коллекции 27 стран лишь на уровне метаданных ${ }^{7}$. Приоритетными направлениями развития быстро растущей электронной мегаколлекции, как явствует из официальной документации [13], являются: содействие экономическому росту стран - членов ЕС через поддержку инновационных начинаний в сфере бизнеса, образования, организации досуга и культурного туризма; активизация культурных взаимосвязей народов Европы; поддержка культурного разнообразия на уровне контента через обеспечение расширенного доступа к культурному наследию европейских стран при соблюдении вектора развития в направлении унификации и стандартизации структурных параметров национальных электронных хранилищ (организации поискового аппарата, ввода метаданных, выбора формата хранения массива данных и пр.).

Открытию DPLA 18 апреля 2013 г. предшествовал ряд всколыхнувших научную общественность статей Р. Дэрнтона ${ }^{8}$, президента библиотечной системы Гарвардского университета, в защиту проекта [14-16]. В чем суть претензий классика американской исторической науки к библиотечному проекту Google? Не случайно Дэрнтон начал кампанию в СМИ против амбициозной корпорации именно в 2009 г., когда очередной виток судебной эпопеи Google увенчался соглашением с Гильдией американских авторов и Ассоциацией американских издателей и фактически трансформировал поисковый сервис в коммерческую библиотеку, обладающую неограниченными финансовыми и технологическими возможностями ${ }^{9}$. Сложилась парадоксальная ситуация: покупая подписку, научные библиотеки могли получить доступ к базе данных Google, т. е. к тем самым цифровым копиям книг, которыми они бесплатно снабдили Google и которые теперь они могли сделать доступными для читателей по цене, установленной Google и его новыми партнерами. Для некоторых, отмечал Дэрнтон, Google Book Search стал выглядеть как новая монополия на доступ к знанию [15].

В результате консенсуса, достигнутого американской библиотечной общественностью, на базе Центра Беркмана (Berkman Center to 
Internet and Society) в Гарварде в 2010 г. были сформированы Инициативный комитет и секретариат, возглавившие работу по формированию новой общедоступной цифровой библиотеки. На протяжении двух с половиной лет в общенациональном масштабе велась интенсивная работа по консолидации оцифрованных библиотечных коллекций в рамках единого каталога; много материалов поступило из Библиотеки Конгресса и Internet Archive. Р. Дэрнтон так сформулировал поставленную задачу: вдохновившись дерзкой попыткой Google оцифровывать целые библиотеки, DPLA надеется победить его как соперника в работе на общее благо [16]. Так удалось ли, по образному выражению Н. Карра, Лиге плюща ${ }^{10}$ преуспеть там, где потерпела неудачу Силиконовая долина? [17].

Открытая 18 апреля 2013 г. при финансовой поддержке фонда Альфреда Слоана (Alfred P. Sloan Foundation), DPLA, по данным Г. Крейна, смогла обеспечить общее информационное пространство для 12 тыс. публичных библиотек, 100 тыс. школ первой и второй ступени и 3200 научных библиотек [18]. Будучи, согласно специальному соглашению, интероперабельной c Europeana, в перспективе DPLA стремится достичь объединения на уровне метаданных с любой электронной библиотекой мира. Цель новой библиотеки как собрания творческих работ всевозможных форматов - сделать наше культурное достояние доступным онлайн и свободным от платы для всех и везде [16].

История создания национальной электронной библиотеки, пронизанная утопизмом и прагматизмом, столь характерными для американской культуры с самого ее возникновения, стала крупным событием современной общественной жизни CША. Как отмечает T. Кармоди, DPLA это прекрасная идея, взять на вооружение амбиции Google по преобразованию материального в цифровое и соединить с гражданским духом общественной библиотечной системы США, обеспечив центральным порталом децентрализованную сеть цифровых материалов из библиотек, музеев, университетов, архивов и других местных, региональных и общенациональных коллекций [19].

Можно сказать, что была достигнута поставленная Р. Дэрнтоном цель создания максимально противопоставленной Google Book Search обширной цифровой библиотеки с некоммерческим доступом к базам данных. Более того, DPLA как новая институциональная парадигма электронной библиотеки, по данным зарубежных аналитиков, стала активно завоевывать международное признание. В 2012 г. Э. Йи писала, что Google и DPLA - противоположности. Компания Google заинтересована в выгоде, DPLA - некоммерческий проект, стремящийся стать высочайшим импульсом продвижения здоровой экологии производства и распространения информации [20].
На наш взгляд, косвенное свидетельство растущей общественной значимости проектов, альтернативных Google Books, - присоединение в октябре 2005 г. к Альянсу открытого контента компании Microsoft, годом позже развернувшей собственный набор книжных сервисов под названием Live Book Search. Любопытно, что осуществляемая в течение двух лет в рамках проекта оцифровка 750 тыс. книг и 80 млн журнальных статей, согласно специальному соглашению, производилась Internet Archive, после чего Microsoft 26 мая 2008 г. закрыл проект и вышел из Альянса открытого контента (при этом 300 тыс. электронных копий, равно как и аппаратура для сканирования, были переданы безвозмездно в Internet Archive).

\section{Современные электронные библиотеки за рубежом: период роста и консолидации}

В гуманитарном сообществе растет осознание фундаментального различия подходов к книге и eе роли в обществе в компании Google и в рамках основополагающих социально-культурных институтов с многолетней историей, каковыми являются библиотеки [21, с. 423]. Становление общедоступных электронных библиотек как социального и культурного института, соответствующего требованиям нынешней эпохи всеобъемлющей компьютеризации, - совокупность содержательных, организационных и технологических процессов чрезвычайной сложности. Трансформация существующих моделей сохранения и распространения накопленного интеллектуального достояния в рамках модернизации библиотечного дела, как показывает анализ зарубежного опыта, предполагает выработку собственных стратегий оперирования на глобальном информационном рынке, отличных от установок IT-гигантов на достижение монополии и коммерческой выгоды, при активном заимствовании разрабатываемого последними нового формата предоставления информационнокоммуникативных услуг.

Согласно емкой формулировке В. Уэллер ${ }^{11}$, библиотеки должны переосмыслить собственную идентичность как поставщики сбалансированной и значимой информации [22], отличной от массива скоротечной информации, свободно циркулирующей в Интернете. Утверждение электронных библиотек в новой роли полноправных агентов информационного рынка ставит их взаимоотношения c Google Search Book в новый контекст, в результате чего - как точка отсчета, оппонент или соратник - книжный сервис мегакорпорации продолжает играть активную роль в выработке новой институциональной парадигмы.

Казалось бы, трудно найти большую противоположность, чем волонтерский проект «Гутенберг» по распространению бесплатных электрон- 
ных копий, запущенный еще в 1971 г., и коммерческий книжный сервис IT-гиганта, тем не менее, их связывает любопытная история взаимоотношений. В 2002-2003 гг., накануне запуска Google Search Book, когда С. Брин и Л. Пейдж создавали новый интерфейс поиска книг на основе поисковика BackRub, они подробно ознакомились с тем, как устроен проект «Гутенберг», но отказались от планов совместной работы. Вспоминая о тех ранних контактах с новорожденной корпорацией, М. Харт фиксировал кардинальное различие подходов к хранению и распространению информационных ресурсов. Google действует сверху вниз, он крайне централизован; проект «Гутенберг», напротив, децентрализован, абсолютно не коммерциализирован, нельзя разместить ни одно объявление на страницах собрания "Гутенберг» [23]. Именно поэтому многие американские университеты после того, как схлынула волна энтузиазма по поводу оцифровки их коллекций Google и выяснилось, что доступ к отсканированному материалу предоставляется только через поисковую машину корпорации и платную подписку, а персональные данные пользователя негласно поступают в ее распоряжение, предпочли иметь дело с некоммерческими Open Content Alliance и «Гутенбергом» [24]. Петр Ковальчук, основатель pecypca Ebook Friendly, говорит, что является фанатом проекта «Гутенберг» не только из-за его истории, но также по причине его ясного интерфейса и хорошо организованной структуры [3].

Безусловное преимущество «Гутенберга» как общественного проекта - тщательность работы с оцифрованными текстами, проходящими трехступенчатую процедуру вычитки через систему «Распределенные корректоры», двухступенчатый процесс форматирования вплоть до окончательной верификации в отличие от Google Search Book, славящегося, как известно, крайней неряшливостью предоставления текстов (зачастую плохо читаемых с многочисленными ошибками в метаданных ${ }^{12}$ ) [25]. Собрав к концу 2015 г. коллекцию в 50 тыс. ед. хр. на десяти языках, в том числе на русском под названием Rutenberg, этот ресурс постепенно (как оказалось, опять-таки не без помощи мегакорпорации, заключив специальное соглашение на использование сервисов Gmail и Google Drive ${ }^{13}$ ) оброс целым набором новейших приложений, дающих возможность получать по электронной почте список ежедневных обновлений (15 тыс. новых книг в месяц), иметь доступ к проекту через мобильный телефон, использовать поисковую машину Google, осуществлять поиск старинных (винтажных) изображений и т. д.

Сам факт неожиданного, казалось бы, продуктивного взаимодействия радикально отличающихся друг от друга проектов указывает на растущую плотность онлайновых взаимодействий электронных хранилищ по мере их роста и развития как на веление времени. Формирование новой институ- циональной парадигмы электронных библиотек предполагает выработку и нового режима сотрудничества - от обмена контентом и стандартизации программного обеспечения до достижения полной интероперабельности разнородных информационных ресурсов. Так, DPLA к середине 2015 г. насчитывала свыше 10 млн ед. хр. из 1600 электронных хранилищ из 20 штатов, поддерживая партнерские взаимоотношения с 16 библиотеками из девяти штатов [26]. В июне 2013 г. DPLA заключила специальное партнерское соглашение с консорциумом HathiTrust Digital Library, откуда в 2015 г. получала не менее трети общего объема своего контента; Internet Archive также является партнером DPLA.

Рост информационно-коммуникативного потенциала DPLA как открытой распределенной сети онлайновых ресурсов ведет к расширению диапазона ее новых услуг, включая: предоставление клиентам возможности пользоваться виртуальными книжными полками, составление перечня приоритетных тем, посещение тематических онлайновых выставок; посредством особых приложений (таких, как Find DPLA для Википедии и WP DPLA для WorldPress) переход на популярные справочные ресурсы и т. д. DPLA располагает также приложением для смартфонов Open Pies, оснащенным GPS для указания тех онлайновых коллекций в составе еe распределенной общенациональной инфраструктуры, которые находятся поблизости от пользователя [26]. Как видим, комфортность и комплексность оказания библиотечных услуг, соответствующих уровню современного технологического развития, более не являются приоритетом Google Search Book, в рамках которого впервые в 2008 г. была, в частности, предложена пользователю услуга по комплектованию личных библиотек (сервис «Моя библиотека» с рубрикацией литературы по виртуальным полкам; приложение Google Play Books в репертуаре Google Play).

Можно констатировать, что стартовавшие под знаком жесткой оппозиции библиотечномy сервису Google общедоступные электронные хранилища на деле много заимствовали у интернет-гиганта: так, консорциум HathiTrust Digital Library ввел аналогичный режим доступа к отсканированным текстам (полнотекстовый - к не подпадающим под закон о защите авторских прав, в выдержках - к защищенным значком копирайта), используя модель, выработанную Google в ходе затяжных судебных разбирательств. Альянс открытого контента, возникший в 2005 г. как открытый академический консорциум для противодействия нацеленному на выгоду проекту Google Search Book, партнерство библиотек и корпоративных спонсоров под управлением Internet Archive [27], тем не менее, подобно оппоненту, никогда не публикует официальных технических отчетов; как и он, не допускает присутствия представителей сканируемых коллекций во время 
процесса оцифровки; также применяет ручное переворачивание страниц при процедуре сканирования; допускает любое свободное использование оцифрованных материалов, за исключением коммерческого.

В целом, можно согласиться с мнением, что научному сообществу далеко до того, чтобы соперничать с успешностью Google в создании мощных интерфейсов цифрового контента, равно как и в мастерстве использования новейших технологических достижений для оптимизации циркуляции знания от поставщика к потребителю [27]. Однако нельзя не признать, что благородный импульс, побудивший научную и библиотечную общественность к выходу за рамки Googleverse ${ }^{14}$ [28], привел к замечательным результатам - построению альтернативных электронных библиотечных систем, располагающих помимо свободного доступа рядом таких преимуществ, как наличие каталога ${ }^{15}$ и корректуры распознанных текстов. Как говорится, дорогу осилит идущий.

\section{Примечания}

1 По данным аналитиков из США, в апреле 2013 г. в рамках программы Google Book Search было оцифровано свыше 30 млн книг из хранилищ 28 библиотек-партнеров по всему миру. При этом, как известно, Google планировал отсканировать все мировое интеллектуальное наследие, ориентировочно оцененное им в 129 млн книг.

2 Брюстер Кейл (Brewster Kahle, p. 22 октября 1960 г.) - популярный американский интернет-активист, основатель интернет-архива и ряда других популярных проектов, член Зала славы Интернета (Internet Hall of Fame).

3 Джилл Грог - специалист по электронным ресурсам в библиотеке Университета Алабамы. Бэт Эшмор - специалист по каталогам библиотеки Стэнфордского университета.

4 Usus (лат.) - способ применения, привычный порядок использования.

5 Использование в названии библиотеки индийского слова hathi (слон) ее учредители мотивируют тем, что это животное - общепризнанный символ мудрости и долголетия.

6 Creative Commons - неправительственная организация, выступающая за расширение доступа к творческим работам, является фрагментом более широкого общественного движения за свободную культуру (Open Culture Movement). Введенная ею система лицензий к 2014 г. охватывала свыше 860 млн публикаций.

7 Согласно специальному соглашению данная модель организации банка данных используется также в DPLA и Корейской электронной библиотеке.

8 Роберт Дэрнтон (р. 10 мая 1939 г.) - известный американский историк, специалист по истории печатной и книжной культуры Европы, особенно Франции XVIII века. Его перу принадлежит свыше 20 книг. Деятельность Дэрнтона, члена Королевской академии французского языка и литературы
Бельгии и Почетного легиона Франции, отмечена множеством наград, в частности премией Гутенберга и американской национальной медалью в области гуманитарных наук.

9 Следует отметить, вопреки распространенному мнению оцифровка фондов библиотечным проектом Google не была для библиотек бесплатной. Так, сканирование 850 тыс. книг из общественно доступного фонда обошлась Гарвардскому университету в 1,9 млн долл. США плюс оформление подписки [16].

10 Лига плюща - ассоциация ряда частных элитарных университетов Северо-востока США (Гарвардский, Принстонский, Йельский, Пенсильванский и т. д.), поддерживающих высокие стандарты качества образования и строгий отбор при приеме абитуриентов.

11 В. Уэллер (V. Waller) - научный сотрудник Института социальных исследований Технологического университета Суинберна в Мельбурне (Австралия).

12 Частые ошибки в метаданных, предоставляемых Google Search Book, позволили некоторым американским аналитикам высказать предположение, что путаница в датах выхода книг производится намеренно с целью вывода их за рамки действия закона о защите авторских прав.

13 Google Drive (иначе Google Диск) - файловый хостинг с функцией хранения файлов в Интернете, общего доступа к ним и совместного редактирования. Сервис начал работать с 24 апреля 2012 г. и к октябрю 2014 г. насчитывал уже 290 млн активных пользователей.

14 Неологизм, возникший из объединения двух слов: «Google» «universe»; буквально: «вселенная Google» - распространенное в американской научной публицистике словосочетание для выражения совокупного действия многообразных сервисов IT-империи, охватывающих практически все стороны жизни человека.

15 Как правило, используется WorldCat - каталог, разработанный и поддерживаемый Online Computer Library Center (OCLC), библиотечной сетью, объединяющей 37 тыс. библиотек в 67 странах мира.

\section{Список источников}

1. Google: 129 Millions Different Books Have Been Published [Электронный pecypc]. URL: http://www. pcworld.com/article/202803/google_129_million_ different_books_have_been_published.html (дата обращения: $17.08 .201 \overline{6})$.

2. Grogg J.E., Ashmore B. Google Book Search Libraries and Their Digital Copies [Электронный pecypc]. URL: http://www.infotoday.com/searcher/apr07/Grogg_ Ashmore.shtml (дата обращения: 17.08.2016).

3. Kowalczyk P. 8 tips and tricks to Get the Most of Project Gutenberg [Электронный pecypc]. URL: http:// ebookfriendly.com/project-gutenberg-tips-tricks/ (дата обращения: 17.08.2016).

4. Hoffelder $N$. Internet Archive Now Hosts 4,4 Million eBooks, Sees 15 Millions eBooks Downloaded Each Month [Электронный pecypc]. URL: http://www.thedigital-reader.com/2013/07/09/ (дата обращения: 17.08.2016).

5. Bergquist K. Google Project Promotes Public Good [Электронный ресурc]. URL: http://www.umich. 
edu/urecord/0506/Feb13_06/02.shtml (дата обращения: 17.08.2016).

6. Baksik K. Fair Use or Exploitation? The Google Book Search Controversy [Электронный ресурс]. URL: https://www.press.jhu.edu/journals/portal_libraries_ and_the_academy/award_articles/6.4baksik.pdf (дата обращения: 17.08.2016).

7. Picker R.C. After Google Book Search: Rebooting the Digital Library [Электронный pecypc]. URL: http:// www.law.uchicago.edu/faculty/research/randal-cpicker-after-google-book-search-rebooting-digitallibrary (дата обращения: 17.08.2016).

8. Helft M. An Elephant Books Up Google's Library [Электронный ресурc]. URL: http://bits.blogs. nytimes.com/2008/10/13/an-elephant-backs-upgoogles-library/ (дата обращения: 17.08.2016).

9. Piper P.S. HathiTrust and Digital Public Library of America as the Future [Электронный ресурс] // Online Searcher. 2013. Vol. 37, № 2, C. 22-27. URL: http://www.infotoday.com/OnlineSearcher/Articles/ Features/HathiTrust-and-Digital-Public-Library-ofAmerica-as-the-future-88089.shtml (дата обращения: 17.08.2016).

10. Eichenlaub N. Checking in with Google Books, HathiTrust and the DPLA [Электронный pecypc] // Computers in Libraries. 2013. Vol. 33, № 9. C. 4-9. URL: http://www.infotoday.com/cilmag/nov13/ Eichenlaub--Checking-In-With-Google-Books.shtml (дата обращения: 17.08.2016).

11. Jeanneney J.-N. Google and the Myth of Universal Knowledge: a View from Europe [Электронный pecypc]. URL: http://press.uchicago.edu/ucp/books/ book/chicago/G/bo4528191.html (дата обращения: 17.08.2016).

12. Gray J.Foundation Europeana Opens up Data on 20 Million Cultural Items [Электронный pecypc]. URL: http://www.theguardian.com/news/datablog/2012/ sep/12/europeana-cultural-heritage-library-europe (дата обращения: 17.08.2016).

13. Europeana - the Case for Funding. What Is Europeana [Электронный ресурс]. URL: http://www.slideshare. net/Europeana_Newspapers/allez-culture-the-casefor-funding-europ (дата обращения: 17.08.2016).

14. Darnton R. Google and the Future of Books [Электронный ресурс] // The New York Review of Books. 2009. Vol. 56, № 2. URL: http://www. nybooks.com/articles/archives/2009/feb/12/googlethe-future-of-books / (дата обращения: 17.08.2016).

15. Darnton $R$. The National Digital Public Library Is Launched! [Электронный ресурс] // The New York Review of Books. 2013. Vol. 60, № 7. URL: http:// www.nybooks.com/articles/2013/04/25/nationaldigital-public-library-launched/ (дата обращения: 17.08.2016).

16. Darnton R. Google's Loss: The Public's Gain [Электронный ресурс] // The New York Review of Books. 2011. Vol. 58, № 7. URL: http://www. nybooks.com/articles/2011/04/28/googles-losspublics-gain/ (дата обращения: 17.08.2016).
17. $\operatorname{Carr} N$. The Library of Utopia [Электронный pecypc] // MIT Technology Review. 2012, 25 anp. URL: https://www.technologyreview.com/s/427628/ the-library-of-utopia (дата обращения: 17.08.2016).

18. Crane G. A Digital Public Library of America and the Transformation of the Humanities [Электронный pecypc]. URL: http://www.perseus.tufts.edu/ publications/dpla/beta-sprint-tufts.html (дата обращения: 17.08.2016).

19. Carmody T. How the Digital Public Library of America Hopes to Build a Real Public Commons [Электронный ресурc]. URL: http://www. theverge.com/2013/4/3/4178980 (дата обращения: 17.08.2016).

20. Yi E. Inside the Quest to Put the World's Libraries Online [Электронный ресурc]. URL: http://www. theatlantic.com/entertainment/archive/2012/07/ inside-the-quest-to-put-the-worlds-librariesonline/259967/ (дата обращения: 17.08.2016).

21. Савиикая T.E. Проект Google Book Search: за и против // Обсерватория культуры. 2016. Т. 13, № 4 . C. $420-428$.

22. Waller $V$. The Relationship between Public Libraries and Google: Too Much Information [Электронный pecypc] // First Monday. 2009. Vol. 14, № 9. URL: http://www.firstmonday.org/ojs/index.php/ $\mathrm{fm} /$ article/view/2477/2279 (дата обращения: 17.08.2016).

23. Project Gutenberg Fears No Google [Электронный pecypc]. URL: http://www.wsj.com/public/ articleSB113415403113218620 (дата обращения: 25.12.2015).

24. Dalton M. Digital Public Library of America to Connect Online Collections across US [Электронный pecypc]. URL: http://mediashift.org/2015/06/ digital-public-library-of-america-to-connect-onlinecollections-across-us / (дата обращения: 17.08.2016).

25. Google Fouls up Again: Google Search Book Is a Disaster for Scholars and Copyright Owners [Электронный ресурc]. URL: http://www.musiktech. policy.worldpress.com/2009/09/27 (дата обращения: 22.12.2015).

26. Cohen D. The Digital Public Library of America: Collaboration, Content and Technology [Электронный pecypc] // EDUCAUSE Review. 2014, July/August. P. 56-57. URL: https://er.educause.edu/articles/ 2014/7/the-digital-public-library-of-americacollaboration-content-and-technology-at-scale (дата обращения: 17.08.2016).

27. Leetaru K. Mass Book of Digitization: The Deeper Story of Google Books and the Open Content Alliance [Электронный pecypc] // First Monday. 2008. Vol. 13, № 10. URL: http://www.firstmonday.org/ article/view/2101/2037 (дата обращения: 17.12.2015).

28. Jones Ph. The Google Digital Library Row Explained [Электронный pecypc]. URL: https:// www.theguardian.com/books/2009/sep/08/googledigital-library-row-explained (дата обращения: 17.08.2016). 


\title{
Google Book Search Project and Alternative Experience of Formation of E-Libraries
}

\author{
Tatiana E. Savitskaya, \\ The Russian State Library, 3/5 Vozdvizhenka Str., Moscow, 119019, Russia \\ E-mail: eneklessa@yandex.ru
}

\begin{abstract}
The article analyzes the role of Google Book Search, the largest corporate repository of information with the subordinate function of pay wall, in the development of new institutional paradigm of e-libraries. It is noted the negative reaction of foreign library community to the functioning of the ITgiant book service as an attempt of monopolizing the access to intellectual heritage. It is described the public benefit concept, triggering the formation of new electronic archives.

The article examines the alternative experience of formation and functioning of some foreign digital libraries: HathiTrust Digital Library, Europeana, Digital Public Library of America, Internet Archive, putting forward the priority of non-commercial access to databases. Attention is paid to the history and basic structural parameters of the emerging electronic collections. The article analyzes the dynamics of relationship of the new digital libraries with Google book service - from active cooperation in digitization programs to opposition against information monopoly practice, and then to sporadic cooperation in the framework of special projects, promoting new format of providing information services. Attention is focused on the development of new principles of collective cooperation of digital libraries abroad in the process of building infrastructure of the information society.
\end{abstract}

Key words: Information Society, Google Book Search Project, E-Library, Project Gutenberg, Live Book Search, HathiTrust Digital Library, Europeana, Digital Public Library of America, Internet Archive.

Citation: Savitskaya T.E. Google Book Search Project and Alternative Experience of Formation of E-Libraries, Bibliotekovedenie [Library and Information Science], 2016, vol. 65, no. 5, pp. 522-530.

\section{References}

1. Google: 129 Millions Different Books Have Been Published. Available at: http://www.pcworld.com/ article/202803/google_129_million_different_books_ have_been_published.html (accessed 17.08.2016).

2. Grogg J.E., Ashmore B. Google Book Search Libraries and Their Digital Copies. Available at: http://www. infotoday.com/searcher/apr07/Grogg_Ashmore. shtml (accessed 17.08.2016).

3. Kowalczyk P. 8 tips and tricks to Get the Most of Project Gutenberg. Available at: http://ebookfriendly.com/ project-gutenberg-tips-tricks/ (accessed 17.08.2016).

4. Hoffelder N. Internet Archive Now Hosts 4,4 Million eBooks, Sees 15 Millions eBooks Downloaded Each Month. Available at: http://www.the-digital-reader. com/2013/07/09/ (accessed 17.08.2016).

5. Bergquist K. Google Project Promotes Public Good. Available at: http://www.umich.edu/urecord/0506/ Feb13 06/02.shtml (accessed 17.08.2016).

6. Baksik K. Fair Use or Exploitation? The Google Book Search Controversy. Available at: https://www.press. jhu.edu/journals/portal_libraries_and_the_academy/ award_articles/6.4baksik.pdf (accessed 17.08.2016).

7. Picker R.C. After Google Book Search: Rebooting the Digital Library. Available at: http://www.law. uchicago.edu/faculty/research/randal-c-pickerafter-google-book-search-rebooting-digital-library (accessed 17.08.2016).

8. Helft M. An Elephant Books Up Google's Library. Available at: http://bits.blogs.nytimes.com/2008/10/13/ an-elephant-backs-up-googles-library/ (accessed 17.08.2016).

9. Piper P.S. HathiTrust and Digital Public Library of America as the Future, Online Searcher, 2013, vol. 37, no. 2, pp. 22-27. Available at: http://www. infotoday.com/OnlineSearcher/Articles/Features/ HathiTrust-and-Digital-Public-Library-of-Americaas-the-future-88089.shtml (accessed 17.08.2016).

10. Eichenlaub N. Checking in with Google Books, HathiTrust and the DPLA, Computers in Libraries, 2013, vol. 33, no. 9, pp. 4-9. Available at: http:// www.infotoday.com/cilmag/nov13/Eichenlaub-Checking-In-With-Google-Books.shtml (accessed 17.08.2016).

11. Jeanneney J.-N. Google and the Myth of Universal Knowledge: a View from Europe. Available at: http:// press.uchicago.edu/ucp/books/book/chicago/G/ bo4528191.html (accessed 17.08.2016).

12. Gray J. Foundation Europeana Opens up Data on 20 Million Cultural Items. Available at: http://www. theguardian.com/news/datablog/2012/sep/12/ europeana-cultural-heritage-library-europe (accessed 17.08.2016).

13. Europeana - the Case for Funding. What Is Europeana. Available at: http://www.slideshare.net/Europeana_ 
Newspapers/allez-culture-the-case-for-funding-europ (accessed 17.08.2016).

14. Darnton R. Google and the Future of Books, The New York Review of Books, 2009, vol. 56, no. 2. Available at: http://www.nybooks.com/ articles/2009/02/12/google-the-future-of-books/ (accessed 17.08.2016).

15. Darnton R. The National Digital Public Library Is Launched!, The New York Review of Books, 2013, vol. 60, no. 7. Available at: http://www.nybooks.com/ articles/2013/04/25/national-digital-public-librarylaunched/ (accessed 17.08.2016).

16. Darnton R. Google's Loss: The Public's Gain, The New York Review of Books, 2011, vol. 58, no. 7. Available at: http://www.nybooks.com/articles/2011/04/28/ googles-loss-publics-gain/ (accessed 17.08.2016).

17. Carr N. The Library of Utopia, MIT Technology Review, 2012, April 25. Available at: https://www. technologyreview.com/s/427628/the-library-ofutopia/ (accessed 17.08.2016).

18. Crane G. A Digital Public Library of America and the Transformation of the Humanities. Available at: http://www.perseus.tufts.edu/publications/dpla/ beta-sprint-tufts.html (accessed 17.08.2016).

19. Carmody T. How the Digital Public Library of America Hopes to Build a Real Public Commons, The Verge, 2013, Apr. 3. Available at: http://www.theverge. com/2013/4/3/4178980 (accessed 17.08.2016).

20. Yi E. Inside the Quest to Put the World's Libraries Online, The Atlantic, 2012, July 26. Available at: http://www.theatlantic.com/entertainment/ archive/2012/07/inside-the-quest-to-put-the-worldslibraries-online/259967/ (accessed 17.08.2016).

21. Savitskaya T.E. Proekt Google Book Search: za i protiv [Google Book Search Project: the Pros and Cons],
Observatoriya kul'tury [Observatory of Culture], 2016, vol. 13, no. 4, pp. 420-428.

22. Waller V. The Relationship between Public Libraries and Google: Too Much Information, First Monday, peer-reviewed journal on the Internet, 2009, vol. 14, no. 9. Available at: http://www.firstmonday.org/ ojs/index.php/fm/article/view/2477/2279 (accessed 17.08.2016).

23. Project Gutenberg Fears No Google. Available at: http:// www.wsj.com/public/articleSB113415403113218620 (accessed 25.12.2015).

24. Dalton M. Digital Public Library of America to Connect Online Collections across US. Available at: http:// mediashift.org/2015/06/digital-public-library-ofamerica-to-connect-online-collections-across-us/ (accessed 17.08.2016).

25. Google Fouls up Again: Google Search Book Is a Disaster for Scholars and Copyright Owners. Available at: http://www.musiktech.policy.worldpress. com/2009/09/27 (accessed 22.12.2015).

26. Cohen D. The Digital Public Library of America: Collaboration, Content and Technology, EDUCAUSE Review, 2014, July / August, pp. 56-57. Available at: https://er.educause.edu/articles/2014/7/the-digitalpublic-library-of-america-collaboration-content-andtechnology-at-scale (accessed 17.08.2016).

27. Leetaru K. Mass Book of Digitization: The Deeper Story of Google Books and the Open Content Alliance, First Monday, peer-reviewed journal on the Internet, 2008, vol. 13, no. 10. Available at: http://www.firstmonday. org/article/view/2101/2037 (accessed 17.08.2016).

28. Jones Ph. The Google Digital Library Row Explained, The Guardian, 2009, 9 September. Available at: https:// www.theguardian.com/books/2009/sep/08/googledigital-library-row-explained (accessed 17.08.2016).

\section{Анонс}

\section{ПРЕДСТОЯЩИЕ КОНГРЕССЫ ИФЛА}

- Всемирный библиотечный и информационный конгресс - 83-я Генеральная конференция

и Ассамблея ИФЛА на тему «Библиотеки. Солидарность. Общество» (Libraries. Solidarity.

Society) состоится 19-25 августа 2017 г. во Вроцлаве, Польша.

- Всемирный библиотечный и информационный конгресс - 84-я Генеральная конференция и Ассамблея ИФЛА состоится в августе 2018 г. в Куала-Лумпуре, Малайзия.

Регионы, где будут проводиться конгрессы в ближайшие годы:

- 2019 - Европа

• 2020 - Азия и Океания 